\title{
Ciudadanía y pobreza ante el avance de la derecha neoliberal: los escenarios de América Latina y México Citizenship and poverty in the face of the advancing neoliberal right-wing: scenarios of Latin America and Mexico
}

Gonzalo Alejandre Ramos ${ }^{1}$

Universidad Autónoma del Estado de México, México gonalra13@hotmail.com

\section{Resumen}

La modernidad fue un recurso que fortaleció a los grupos de la derecha. El poder de esta ha crecido al amparo de los estados hasta apoderarse de los recursos del planeta e iniciar el despojo del resto de la población más vulnerable, la cual en su marginalidad es cada vez más incapaz de oponerse y de buscar alternativas al desequilibrio. Las acciones orientadas a restablecer una correlación de fuerzas son cada vez más escasas e ineficaces, las luchas sociales son hoy, en el mejor de los casos, solo sueños y recuerdos; los movimientos sociales son esporádicos y de poco alcance, meras válvulas de escape, incluso ya disfuncionales al sistema global. Los países pobres son productores de migrantes hacia países desarrollados. El Estado y sus instituciones se han vuelto comparsa de los grupos dominantes en un escenario de globalidad neoliberal. Ante este panorama, la democracia y la ciudadanía son conceptos carentes de contenido. Por otro lado, la academia y la intelectualidad universitaria son forzadas a servir a los dominadores, pues ya no ofrecen alternativas que desvanezcan un escenario sin límites que proyecta un casi inminente colapso de la humanidad. Es imprescindible que reflexionemos y actuemos al respecto.

Palabras clave: ciudadanía, democracia, neoliberalismo, Estado, pobreza.

${ }^{1}$ PTC en la Universidad Autónoma del Estado de México, C.U UAEM Zumpango, correo electrónico: gonalra13@hotmail.com 


\section{Abstract}

Modernity was a resource that strengthened the right-wing groups. The power of the aforementioned has grown under cover of the States to take over the planet's resources and initiate the plunder of the rest most vulnerable population, which is increasingly unable to oppose and seek alternatives to the imbalance in their marginality. Actions to restore a correlation of forces are becoming more scarce and ineffective, social conflicts are today, in the best of cases, only dreams and memories; social movements are sporadic and little scope, mere exhaust valves, even already dysfunctional to the global system. Poor countries are producers of migrants to developed countries. The State and its institutions have become companions of dominant groups in a scenario of neoliberal globalization. Faced with this panorama, Democracy and Citizenship are lacking content concepts. On the other hand, the Academy and the University intelligentsia are forced to serve the dominators, since they do not offer alternatives in order to fade a scenario without limits that projects a near imminent collapse of humanity. It is imperative that we think and act in this regard.

Key words: citizenship, democracy, neoliberalism, State, poverty.

Fecha Recepción: Junio $2015 \quad$ Fecha Aceptación: Noviembre 2015

\section{Introducción}

El mundo vive desde finales del siglo XX y lo que va del XXI un proceso de agotamiento del discurso y de las formas de acción social. El equilibrio social históricamente vivido y definido por la existencia de una correlación de fuerzas cada vez es menor como recurso viable ante la dominación de las fuerzas conservadoras que ganan hoy todos los espacios del planeta.

Los estados nacionales han dejado de ser barreras u obstáculos, sus instituciones se han debilitado, los grupos de poder económico suman triunfo tras triunfo, su ideología de 
ganar-ganar se impone en todos los rincones del planeta y no encuentran límites. Las clases políticas de los estados más vulnerables que aún conservan algo de poder, cuando no son derrotadas se suman a los vencedores y detentadores de la riqueza, la cual cada día está más acumulada. El mundo se polariza, la política en todas partes ha demostrado una y otra vez su fracaso, ante una realidad donde el poder económico aquí y allá impone las reglas. Los procesos electorales tradicionales cada vez son menos creíbles, la democracia se muestra como una palabra sin contenido, el concepto y la práctica ciudadanas que le dieron sentido a la sociedad y al Estado tradicionales se han caricaturizado, moviéndose solo por interés pecuniario o por la supervivencia ante la creciente pobreza y la ineficacia política. El estado protector es solo un recuerdo ajeno de lo que propuso la realidad del viejo mundo europeo y que en los países coloniales no tuvo tiempo de madurar; nació caricaturizado y sin vida política, realidad en donde las necesidades han reinado históricamente.

Un factor histórico central ha sido el discurso ideológico que separa la realidad en partes, por un lado la economía y por otro la política como campos que no se tocan, cuando la realidad cotidiana de todo individuo requiere de ambos. La separación que nos trajo la modernidad ha despedazado al mundo y propiciado el dominio de unos cuantos, quienes han creado el discurso del orden social y político puesto a su servicio, ese orden implantado por la derecha que se ha apoderado de todo, de los recursos del planeta, agua, aire, bosques, mares, tierra minerales, petróleo, y voluntades de la población. Este es un mundo de desesperanza donde no hay ya protección para los que por fuerza se han convertido en débiles; sin embargo, en este escenario de desequilibrio subyace el peligro a la supervivencia tanto de ricos como de pobres.

Por otro lado, es una realidad lamentable que las distintas ciencias con todos sus avances al servicio de los dominadores de la derecha, no logran encontrar una solución al problema de los excesos de ambición de los dominadores. La academia universitaria y su teoría social son prescindibles para los que han logrado dominar el mundo, sus saberes son vistos hoy sin aparente correlación con la lógica de hacer negocios y ganar.

La política, la democracia, la ciudadanía, las elecciones que legitimaron al Estado ceden ante la derechización del mundo, y en su lugar crece la violencia, gana la desesperación; comprar y vender seguridades se vuelve un nuevo negocio, un gran negocio, una "nueva 
mercancía" no objetivada que inició en el campo formal y no conforme con eso ha invadido el mercado informal. Hemos vuelto al inicio, la mercancía que fue mediada por el dinero cede nuevamente a la mercancía, pues el dinero se ha convertido en ficción, el círculo mercancía-dinero-mercancía se convirtió en dinero-mercancía-dinero. Hoy en la cúspide del desarrollo regresamos al inicio, el dinero se ha esfumado y cada vez es más una ficción. Somos primitivos modernos.

Con este panorama permeando en el mundo, el presente análisis se centra en las realidades constituidas por países de clase política más debilitada, ahí donde este acontecer tiene más y mejores expresiones de la nueva barbarie como es el caso de América Latina, y para muestra analizaremos el caso particular de México, donde está sucediendo a distintas escalas e intensidades lo que sucede en todo el orbe. Los efectos de la creciente polarización riqueza-pobreza que reporta Oxfam, ${ }^{2}$ es riqueza en los paraísos fiscales y no en la inversión productiva, lo peor de todo es que con seguridad lo único que crece es el control del resto de la población del mundo. Los poderes dominantes así lo exigen, parece ser esa una realidad irreversible. Las migraciones masivas de norte a sur son un indicador de la crisis del modelo económico global, la gente desvalorizada trata de salvar lo único que le queda: la vida. La desesperación parece estar controlada, los medios de comunicación están sirviendo para modelar las acciones y reacciones de las masas, el miedo se ha convertido en el acompañante cercano de todos, nadie está a salvo, quien valora su vida y tiene los recursos invierte en su seguridad.

En este ensayo, el texto de Marshall: Citizenship and Social Class nos servirá como un buen punto referencial para argumentar la situación a la que nos ha conducido el acontecer del mundo global y los efectos que provoca en los conceptos de ciudadanía, Estado y democracia, entre otros. Todos ellos en proceso de transformación alejados de la realidad, un ciudadano concreto y real, una democracia y un Estado que han rebasado los postulados liberales; en un mundo global donde el discurso político y económico son ya insuficientes para mantener separadas e independientes la economía de la política y negar en los hechos que el homo economicus es a la vez homo politicus.

\footnotetext{
${ }^{2}$ Oxfam es una confederación internacional formada por 17 organizaciones no gubernamentales nacionales, que ha destacado la desigualdad creciente entre países y entre la población, producida por el modelo económico vigente, sobre todo las desigualdades de la población al interior de los países más pobres.
} 


\section{Factores socioeconómicos de la transformación ciudadana}

Si bien el concepto de ciudadanía y el ciudadano real, tienen como referente obligado la situación política de la antigua Ciudad Estado griega, estos son muy distintos en nuestro mundo moderno, sobre todo cuando aparece la producción industrial como el producto de la ciencia convertida en tecnología, lo cual ha generado momentos históricos de grandes rupturas.

Uno de estos momentos es, sin duda, la Segunda Guerra Mundial, después de esta, el concepto de ciudadanía tiene como su expositor más influyente a T. H. Marshall en su paradigmático libro Citizenship and Social Class escrito en 1949, sin embargo, no tuvo gran relevancia, pues hacia finales de la década de los setenta del siglo XX había caído en el olvido. Kymlica y Norman (1997) afirman que el concepto de ciudadanía hacia 1978 prácticamente ya era obsoleto en el ámbito de la academia.

Sin embargo, a partir de la década de los años noventa del siglo $\mathrm{XX}$, el concepto se ha convertido en una palabra que suena a todo lo largo del espectro político y entre los pensadores en esta materia, según recuperan autores como Heater (1990, p. 293) o Vogel y Morgan (1991, p. x), quienes aducen que hay una serie de razones que explican este renovado interés a partir de la última década del siglo XX (Kymlica y Norman, 1997, pp. 17).

Este interés reorienta el discurso político con base en la realidad cambiante del mundo moderno, la polaridad sistémica capitalismo-socialismo quedó rebasada, la lucha entre estados tampoco es ya la centralidad, el enemigo de los grupos de interés se ha reconfigurado ante el panorama de la globalidad. La política y la economía son cada vez más indiferenciadas, las fuerzas conservadoras y neoconservadoras enfocan sus baterías hacia la observación de los individuos concretos que viven sus carencias y necesidades, como ciudadanos que exigen justicia y definir su sentido de pertenencia social comunitaria.

Hoy en día, el concepto de ciudadanía vive un proceso de reconfiguración ante el dominio de los grupos económicos. De esa manera, el concepto se convierte nuevamente en central ante la transformación del mundo económico que afecta las formas de vida y las perspectivas de acción social y política; según Kymlica y Norman (1997), “el interés en la 
ciudadanía ha sido también alimentado por una serie de eventos políticos y tendencias recientes que se registran a lo largo y ancho del mundo: la creciente apatía de los votantes y la crónica dependencia de los programas de bienestar" (Kymlicka y Norman, 1997, p. 6).

Una serie de acontecimientos han sido fundamentales para retomar el tema de la transformación de la ciudadanía, entre los cuales podemos destacar: la caída del discurso radical de derecha, basado en el mundo bipolar del sistema capitalista y socialista, el fracaso estadounidense en la Guerra de Vietnam, el debilitamiento ideológico del mundo occidental basado en el estado liberal democrático, y la caída del bloque socialista.

Al desestructurarse las bases ideológicas del capitalismo, este optó por robar en parte las banderas del socialismo con la implementación del estado providencia, lo cual ha generado un importante cambio en las acciones tradicionales. No obstante, este hecho en la práctica provocó la aparición de las nuevas derechas, tanto en Europa, Estados Unidos y América Latina. La nueva derecha, a decir de Finkielkraut (1982), es una reacción de los conservadores ante el desvanecimiento de su fuerza ideológica y política, y el paulatino avance del bienestarismo social para individuos y clases pobres. De ahí la reacción de la nueva derecha de la era Tatcher-Reagan, que considera que el estado liberal tiene una postura débil y que más que favorecer el progreso, dicho estado lo ha frenado y se ha convertido en un obstáculo. Esa misma idea sostuvieron los Chicago boys, quienes critican al estado keynesiano por intervenir excesivamente en la economía (Finkielkraut, 1982, p. 44).

La nueva derecha sostenía la idea de que el Estado se había convertido en un freno al desarrollo capitalista y que era nocivo su papel interventor, opinaba que "en la época del intervencionismo estatal, el capitalismo está moribundo. Hay que insuflar vida" (Finkielkraut, 1982, p. 45). A juicio de la nueva derecha, el gran defecto del estado keynesiano o estado providencia, es haber incluido a los pobres, cuando estos se encuentran faltos de capacidad competitiva y solo esperan la benevolencia del Estado. Los pobres al vivir a costa del Estado han agudizado la crisis estatal, este se ha vuelto pasivo, ha aumentado su debilidad y retrasado el progreso del mundo moderno, ha asumido una carga 
difícil de llevar, cuyos casos particulares afectan al resto del mundo creativo y con capacidad de emprendimiento.

La nueva derecha es el origen de los neo-economistas, que denuncian la improductividad del estado, critican el asistencialismo y en contraparte se propusieron implementar lo que denominaron un impuesto negativo que beneficie a los más pobres, sin que se les regale nada. "Dicho impuesto negativo tendría una doble ventaja: ejercería una acción real sobre la miseria, pero costaría menos a la colectividad que los actuales métodos de redistribución, a la vez que acabaría con los nocivos efectos del principio de gratuidad" (Finkielkraut, 1982, p. 48).

Otras fórmulas de los neo-economistas como el francés Thomas Piketty (2014), plantean una propuesta para resolver el problema de la desigualdad social que para algunos economistas luce novedosa: un impuesto progresivo a la riqueza, la cual se operaría mediante una política fiscal a nivel mundial, en concordancia con las formas en que opera la globalización; sin embargo, esta propuesta requiere de la creación de mecanismos a nivel mundial que eviten la real capacidad de evasión fiscal del capital. Aquí la pregunta obligada es: ¿qué organismo puede hacer esto? El gravar al capital en la época donde los flujos de capital son libres y van hacia aquellos estados-nación donde les ofrecen mejores ofertas, ¿aceptarían restricciones cuando su principio fundamental es la libertad, incluida la de los flujos de capital?

De igual manera, los dueños del capital se pueden organizar, de hecho lo hacen, en las reuniones que periódicamente realizan en el Club Bilderberg. Como bien lo apunta Cristina Martín (2008), todo parece indicar que los grandes capitales se encuentran por encima de toda normatividad y su acato tiene múltiples fisuras. De ahí que la desigualdad parece ser funcional al sistema productivo, además la nueva derecha tiene medios para mantenerla y eficaces mecanismos de evasión de impuestos para no someterse en los hechos a ninguna ley, pues no bastan las leyes, es necesario un poder suficiente y superior que esté por encima del capital para someterlo, ¿es eso posible hoy?

El liberalismo como sustento ideológico de la nueva derecha mantiene una postura que lo rebasa, ha dado origen a un revanchismo político (Finkielkraut, 1982). La nueva derecha, tanto norteamericana como europea, encuentra una buena justificación en las ideas liberales 
expuestas por Marshall, las cuales son recuperadas tanto en los círculos políticos como en las investigaciones académicas. Este fue un factor que incidió en la paulatina pérdida de fuerza del concepto y de la realidad en torno a la clase social de los trabajadores, prevaleciente desde los postulados teóricos del marxismo.

Los ataques de la nueva derecha desde el poder político han sido certeros y han incidido en la idea y praxis de la organización y la lucha de los trabajadores, pero estos se empiezan a debilitar, con lo cual el enriquecimiento de los más ambiciosos ha sido más fácil y la nueva derecha ahora se manifiesta ideológicamente como el neoliberalismo.

Según Marshall:

... el desarrollo de las clases, entre otras cosas, erosiona y limita la capacidad de la ciudadanía para crear accesos a los recursos escasos y a la participación en las instituciones que determinan su empleo y distribución. La clase y la ciudadanía son principios de organización opuestos: son básicamente tendencias contradictorias (Heald, 1997, p. 42).

Asistimos a partir de las ideas de Marshall al reciclaje de la idea de ciudadano, una nueva y singular idea de unidad, potencialmente capaz de construir otra realidad a partir de una postura ideológica con bases conservadoras. En este contexto, la ciudadanía tiene que ver con las prácticas cotidianas y libres de individuos libres que puedan expresar sus capacidades.

Marshall, al estudiar la realidad de la ciudadanía desde la perspectiva liberal, propuso conceptualmente dividir su estudio en tres partes, a saber: la civil, la política y la social. La civil la concibió como todos los derechos necesarios para la libertad individual, de persona y de expresión, de pensamiento, de religión, de propiedad, etcétera. La parte política la concibió como el derecho a participar en la elección del poder político, como autoridad política o como elector de autoridades. Y la parte social la refirió como el espectro que cubre desde el derecho a un mínimo bienestar económico y seguridad, hasta el derecho a participar del patrimonio social; asimismo, concibe a la ciudadanía como producto de un proceso en constante evolución que tendrá que ir cambiando (Marshall, 1997). 
El ciudadano aparece más ligado a esa visión económico-liberal a la que se le ha adjuntado el fin político de la democracia, la cual funge como el medio político y legitimador de un sistema, cuya unidad central es ahora el individuo y no la colectividad. La democracia no precisamente se ve favorecida con un Estado providencia, pues de acuerdo con los neoliberales "cuanto más aumenta la influencia del poder público, más falseadas resultan las reglas elementales de la democracia” (Finkielkraut, 1982, p. 46).

El retraimiento del estado de bienestar obligó a delegar en el individuo toda la responsabilidad de su destino, la invención de la ciudadanía en sus dos acepciones principales: la ciudadanía como un derecho (legal) que incluye los derechos civiles que aparecen en el siglo XVIII y los derechos políticos que se afirman en el siguiente siglo, y la ciudadanía como una conquista (meritocrática) han sido de gran utilidad, pues ligan al individuo junto con sus supuestos derechos y sus potenciales capacidades a dos campos de la tendencia histórica del mundo: la política y la economía.

Las concepciones del homo politicus y el homo economicus, como concepciones universalistas e ilustradas, con toda la complejidad que les es inherente, han servido para ocultar la perversidad de los ambiciosos que persisten históricamente en el dominio del mundo, ven al planeta únicamente como materia prima para una producción y un crecimiento económico que no se plantea límites.

La tónica cristiana del estado de bienestar, ha sido un impasse breve que solo sirvió para justificar las etapas posteriores de mayor violencia hacia los más débiles, excluidos de compartir los productos de un esquizofrénico crecimiento económico medido de manera muy general por el producto interno bruto (PIB), pues como señalaba Dahrendorf, a los más ambiciosos les resulta inconcebible que "China e India tengan un PIB per cápita como el norteamericano" (Dahrendorf, 1997, p. 139).

Sin embargo, el ritmo de crecimiento y consecuentemente de cambio social no se ha detenido, la ciencia y la tecnología hasta ahora han podido resolver los problemas de la producción de bienes diversos, incluidos los alimentarios, pero la distribución de estos bienes y alimentos presenta una tendencia regresiva. El discurso de los ambiciosos ha recurrido a la compra de hombres de ciencia, quienes niegan la finitud de los recursos naturales del planeta. La realidad muestra que esto conducirá al colapso si se agotan los 
recursos naturales que el sistema productivo ha explotado sin miramientos, y si se sigue insistiendo en que no hay conflicto entre la economía y la ecología. El discurso neoliberal difunde un optimismo infundado que confía en que, en última instancia, la ciencia y la inteligencia humana puedan resolver cualquier contingencia.

En este escenario, las soluciones más probables no contemplan el reparto equitativo de la riqueza, ni la justicia hacia los más pobres del mundo; bajo ninguna circunstancia los más ambiciosos renunciarían a su libertad de enriquecerse, y para ello están dispuestos a usar la violencia del Estado en nombre de la libertad, y convertir así en enemigos a los luchadores sociales. Como bien vaticinó Thomas Jefferson: “el árbol de la libertad debe ser regado de tanto en tanto con la sangre de patriotas y tiranos" (Jefferson en Dahrendorf, 1997, p. 140). La ideología liberal es justificada y sustentada por los propios liberales, quienes se han convencido a sí mismos de que el reparto de la riqueza acumulada es un desperdicio y un derroche que empobrecerá más al mundo.

\section{Desarrollo y ciudadanía en el neoliberalismo}

Es una realidad que los derechos sociales aún no se han logrado afianzar en todo el siglo $\mathrm{XX}$, y que en el XXI inician un severo retroceso; la obsesión por el crecimiento está provocando acciones de supervivencia de los habitantes de los países más pobres, lo cual da origen a dos procesos que inciden sobre la reconfiguración del concepto de ciudadanía: por un lado la disminución de su politización como individuos, y por otro su paulatina conversión en entes consumidores de mercancías.

La concepción de un ciudadano como parte de un estado políticamente construido con su participación, es virtualmente ya una categoría inexistente, al igual que ese tipo de Estadonación, el cual se basó en la imaginación de lo posible. Hoy es menester destacar que el papel central del desarrollo como logro económico ha funcionado de aliciente, de carnada para que los estados más pobres y sus gobiernos hayan sido convencidos $\mathrm{y}$, consecuentemente, emprendido acciones y creado instituciones y organizaciones en busca del desarrollo. 
Sin embargo, estas acciones se caracterizan por carecer de horizontalidad y autonomía de los posibles beneficiados, y consecuentemente los resultados han sido insuficientes para eliminar la desigualdad del mundo moderno. Se observa que en los estados llamados en desarrollo crece la inestabilidad por razones de supervivencia, y para aliviarla la receta es más de lo mismo, han tenido que abrir sus fronteras a las empresas globales, con lo cual los individuos o ciudadanos han quedado más vulnerables y más pobres. Incluso T.H. Marshall reconoce que "la ciudadanía misma se ha convertido en el arquitecto de la desigualdad social legítima" (Marshall, 1997, p. 302).

Está claro que un crecimiento sin desarrollo equitativo del mundo contemporáneo, incide en la reconfiguración de la ciudadanía, lo que ha provocado que la antigua politización se vuelva una especie de conciencia ciudadana que apoya los movimientos ecologistas, los cuales están más identificados con las capas medias de la sociedad, sector de la población que ha recibido una educación que le permite tener más conciencia de lo que está sucediendo en el planeta. Esto amenaza no solo a los más pobres, sino también a dichas capas sociales en los distintos países del mundo, lo cual habla de que ese crecimiento desmedido y falto de equidad está produciendo mayor conciencia social, tanto desde el fenómeno de la supervivencia, como mediante los movimientos vinculados a la preservación del medio ambiente.

Son las clases políticas locales de los distintos estados, pero sobre todo las clases empresariales, las que ahora aglutinan y manejan a manera de propiedad los recursos del mundo, tales como agua, aire, energéticos y la biodiversidad, todos ellos recursos elementales para la existencia. Este acontecer del progreso desmedido e inconsciente y hasta cierto punto innecesario, está agotando los recursos naturales, además está desbordando la capacidad de convivencia de todos los niveles y capas sociales.

Hoy estamos en presencia de la formación de la nueva ciudadanía, una no necesariamente producida por la participación básicamente en los momentos y hechos electorales, ni tampoco por la acción de los individuos en espacios acotados o delimitados por lo territorial y la institucionalidad del Estado y sus reglas jurídicas, sino más bien por "el espacio, que es producto de prácticas, trayectorias e interrelaciones. [...] hacemos espacio mediante las 
interrelaciones en todos los niveles, desde las llamadas locales hasta las denominadas globales" (Massey, 2013, p. 30).

Es un hecho que está surgiendo una ciudadanía producida por una conciencia ecológica, como también por las acciones e interrelaciones motivadas por necesidades ingentes, las cuales ya no empatan necesariamente con las delimitaciones de una ciudadanía pasiva y electoral. Los movimientos por la supervivencia se dividen entre los que permanecen en sus espacios creados por sus interrelaciones y los que crean nuevos espacios en sus procesos migratorios. Tanto la supervivencia como la conciencia, ambas catalizadas por el modelo económico, están incidiendo en la reconfiguración de la ciudadanía.

La Organización de las Naciones Unidas (ONU) señala que está plenamente comprobado que los recursos alimentarios que se producen en el mundo aún son suficientes para toda la humanidad.

La producción alimentaria ha seguido aumentando sostenidamente, a un ritmo superior al del crecimiento de la población; no obstante, hay en todo el mundo 925 millones de personas que están hambrientas. La Organización de las Naciones Unidas para la Alimentación y la Agricultura estima que las pérdidas y el desperdicio de alimentos a escala mundial llegan a 1300 millones de toneladas por año, aproximadamente una tercera parte de la producción mundial de alimentos para consumo humano" (ONU, 2012, p. 2).

Los alimentos son objeto de comercialización con fines de lucro, con lo cual una gran parte de la población mundial queda marginada si carece de recursos para adquirirlos. Sin embargo, volver al Estado providencia es algo que no está en los planes de los grupos conservadores que hoy se han posesionado de los recursos del planeta. 


\section{Democracia y desarrollo en América Latina}

En los distintos países de América Latina, la democracia y el desarrollo son más discursos que realidades, la principal protagonista de ese resultado es la nueva derecha que surgiera como una réplica de la europea y la norteamericana, en consonancia con las ideologías conservadoras en el mundo occidental, por lo cual propone una democracia liberal en el marco histórico derivado de lo que fuera la polarización ideológica que generó la Guerra Fría. La nueva versión del conservadurismo no se define a sí misma como una postura ideológica, sino que más bien suscribe la idea del fin de las ideologías (Fukuyama,1992) como una trayectoria que apunta hacia el cambio social de manera radical hacia la desaparición de los sujetos como entidades con proyectos de cambio social.

La nueva derecha se caracteriza por una postura neo-economicista que postula una disminución del poder político del Estado, lo cual conlleva una crisis del nacionalismo. Así, "la crisis nacional y regional de América Latina ha merecido la atención de investigadores, gobiernos, organismos regionales e internacionales, así como de las distintas fuerzas sociales y políticas de los países del área” (Jiménez, 2002, p. 1).

En este contexto surge en América Latina la idea de democracia, la cual nace en un ambiente histórico que la va moldeando y haciendo distinta de la de otros contextos occidentales, a decir de Hinkelammert en América Latina, sobre todo en el Cono Sur, "la nueva derecha es heredera de las dictaduras militares de Seguridad Nacional, y su vocación es asegurar el esquema de poder originado por esas dictaduras bajo formas democráticas, en beneficio de las élites y con la bendición de Estados Unidos” (Hinkelammert, 1988, p.1).

Por lo tanto, lo que se ha denominado procesos de democratización en América Latina, es más bien una democracia que podemos ubicar en dos situaciones centrales. Por un lado son democracias enmarcadas en el contexto territorial y jurídicamente establecido de los estados nacionales, desde los cuales se encauza una democracia instrumental y funcional a los grupos o élites políticas y económicas. Para Hinkelammert (1988), "la actual etapa de democratización en América Latina se caracteriza por su sentido instrumental, que deja de lado toda auténtica integración participativa de la población” (Hinkelammert, 1988, p. 1). Por otro lado, vemos una demanda de democracia desde una ciudadanía atrapada y sin una 
salida visible que excluye la participación de los ciudadanos en la construcción de la democracia, mediante la cual estos buscan rehacer sus propios espacios políticos y participativos a partir de su realidad y acción cotidiana.

La nueva derecha en América Latina es una postura ideológica en lucha contra los intentos de liberación del colonialismo interno de la región denunciado por los intelectuales de izquierda como Pablo González Casanova en México, quien planteara desde la década de los sesenta una alternativa nacional para el desarrollo social con enfoque de una sociología del desarrollo; o como Fernando H. Cardoso y Enzo Faletto en Brasil, que plantean una visión de desarrollo desde la dependencia en la región (Werz, 1995).

Dese la década de los sesenta en América Latina se percibieron alternativas para la conformación de los estados y las sociedades de la región al margen de la histórica influencia norteamericana. Así, "ante el avance de proyectos alternativos de nación en Latinoamérica, se analiza lo que sugiere ser una (re)articulación de la derecha no solo a nivel interno como oposición a gobiernos alternativos, sino de la región en general y en ocasiones con claro vínculo a intereses foráneos, especialmente estadounidenses" (Romano y Delgado, s.f., p. 1).

Desde la década de los sesenta la influencia del modelo socialista cautivó a varios países de América Latina, vieron en ello una alternativa ante el histórico intervencionismo de Estados Unidos sobre la región, el cual data al menos desde el proyecto del panamericanismo de finales del siglo XIX (Smith, 1977). Así y de manera sistemática:

Desde inicios de los años sesenta, la Agencia para el Desarrollo Internacional (AID) fue una de las entidades encargadas del entrenamiento de la policía de las ciudades capitales de América Latina, a los fines de garantizar la "seguridad interna" (United States Department of State. Foreign Relations, 1961-1963, Vol XII, Doc. 90), contribuyendo a la desestabilización de gobiernos democráticos que fueron reemplazados por gobiernos militares (Romano y Delgado, s.f, p. 2). 
De esta manera, cada país de América Latina ha vivido una democracia vigilada por la nueva derecha estadounidense y por la nueva derecha de la región, la cual en varios casos se ha convertido en Estado. México es una historia de intervencionismos menos directos que el militarismo del Cono Sur, aquí los mecanismos económicos han sustituido el uso de la fuerza. El Tratado de Libre Comercio de América del Norte (TLCAN), firmado por México y vigente desde 1994, incluye aspectos clave para la posesión empresarial de los recursos naturales del país, e influye de manera importante en la vida económica, política e institucional (Aboites, 1999) a la que casi nada escapa, y si otros "capitales amigos" entran a México son vigilados mediante todo un sofisticado sistema de espionaje que los mantiene bajo control.

\section{Democracia y ciudadanía en México}

México forma parte de América Latina, sin embargo, su posición geográfica lo hace más vulnerable a las presiones norteamericanas, lo cual incide en la reconfiguración de la ciudadanía. Los factores económicos a nivel mundial son fundamentales y hasta centrales, en tanto las economías locales dependen de los imponderables flujos de los capitales, donde el TLCAN y los distintos bloques son ahora, por así decirlo, los nuevos mega-estados.

La tendencia macroeconómica ha provocado el debilitamiento progresivo del Estadonación; en México, por ejemplo, sucede lo apuntado por Kymlicka y Norman (1997) para el acontecer mundial: la globalización está provocando un resurgimiento del concepto de ciudadanía. Pero en este caso, el Estado ya no puede abanderar ni cohesionar y menos proteger, ante tal abandono se está operando un despertar de la ciudadanía, distinto a los objetivos e intereses del Estado y la globalización. Esta ciudadanía busca conformar identidades colectivas por sí misma en los espacios locales.

En la época de la globalización, la búsqueda de lo comunitario se da de manera conjugada con su papel de individuos, estos vinculan a la ciudadanía con un fin: el logro de la democracia, distinta a la que pretende el Estado, donde la participación política está 
direccionada hacia los procesos político-electorales y el ciudadano es pasivo y solo espera indicaciones.

Los partidos políticos en la época de la globalización han perdido representación como los medios tradicionales para la renovación del gobierno; paralelamente el Estado mexicano se transforma y se hace presente solo mediante el discurso de la seguridad, tanto ciudadana como nacional, que le sirve de base para desplegar acciones represivas de manera indiscriminada contra lo que califica de delincuencia y crimen organizado. Pero en los hechos no se observa eficacia para solucionar este flagelo emergido como efecto del proceso de globalización. Ambos, globalización y delincuencia organizada, están provocando los movimientos migratorios de población pobre y marginal, acosada por las amenazas y en muchos casos cumplidas de la delincuencia organizada, todo ello ante un Estado testigo inexplicablemente indiferente.

Migración, ciudadanía y desarrollo

Uno de los efectos de la globalización es la migración, tanto la voluntaria como la denominada forzada; "en las economías débiles, la gente sale para escapar a la vez del empobrecimiento y del abuso de los derechos humanos" (Gzesh, 2012, p. 232). Los motivos para migrar pueden ser múltiples, lo cual hace difícil distinguir entre los migrantes económicos y los refugiados. La migración, cualquiera que sea su motivo, tiene efectos sobre el desarrollo tanto de los países receptores como de los expulsores. En lo que toca a la parte social, específicamente a la ciudadanía, muestra una dinámica interesante que da cuenta del problema de su vulnerabilidad, pues el Estado del que emigran deja de darles cobertura y al que llegan les niega derechos y los discrimina, por lo tanto, queda en vilo su derecho civil a la ciudadanía, que se convierte también en un problema de derechos humanos.

En la época de la globalización, la migración es un fenómeno creciente, en especial de los países pobres hacia los ricos, basado en principios de una especie de derecho natural de los individuos, quienes buscan su bienestar en ocasiones migrando de su país de origen. La 
Declaración Universal de 1948, en su artículo 13 proclama: “1. Toda persona tiene derecho a circular libremente y a elegir su residencia en el territorio de un Estado. 2. Toda persona tiene derecho a salir de cualquier país, incluso del propio, y a regresar a su país" (citado en (Velazco, 2013, p. 28).

Hablar del derecho a la libre circulación de las personas en el mundo es adentrarse en un campo minado de paradojas, por no decir de flagrantes contradicciones. De entrada, que el conjunto de la superficie del planeta que habitamos todos fuera accesible a cualquiera que pretenda y pueda desplazarse debería ser algo completamente normal. Al fin y al cabo, la Tierra entera es propiedad común de la humanidad (dicho sea esto con el permiso de las otras especies animales que habitan el planeta), una propiedad que cada generación recibe como herencia inmerecida (Velazco, 2013, p. 28).

A partir de la entrada en vigor del TLCAN firmado por Estados Unidos, México y Canadá, cobró relevancia el discurso sobre la búsqueda del desarrollo en México y se proyectó como el medio de mejora en general de su población, sin embargo, a medida que avanzan las fases del TLC, este desvela que el desarrollo no es posible a corto o siquiera mediano plazo, sino solo conservando e incrementando el consumo de mercancías, lo cual no necesariamente se vincula con el desarrollo, y sí ha disparado el fenómeno de la migración, sobre todo de la población excluida, marginada y desempleada que el modelo de desarrollo produce. En especial se ha incrementado la emigración histórica hacia Estados Unidos en magnitudes exponenciales en busca del empleo que no se consigue en el país.

El modelo económico neoliberal implantado por la nueva derecha hace énfasis en la publicidad para acelerar el consumo de las mercancías que produce. Consumir se ha vuelto condición del nuevo Estado, y para el ciudadano una especie de obsesión en la que están inmersos tanto los productores como los potenciales consumidores, además de los publicistas quienes juegan un papel de primer orden. 
Es posible vincular el deseo de consumo provocado por la publicidad comercial como un motivo importante para la migración, tanto del campo a la ciudad como de un país a otro. "Estudios sobre migración para las ciudades reflejan este fenómeno. La posibilidad de consumir, aunque sea una vez en la vida una cosa diferente, o la posibilidad de ver los objetos en exposición, hacen que el individuo prefiera vivir mal en la ciudad en lugar de quedarse en el interior" (Barreto, s.f., p. 11). Ahora proliferan las migraciones, tanto en el interior como hacia el exterior del país por motivos de supervivencia y de deseos de consumo.

La ciudadanía social se ha convertido en una praxis de los individuos con necesidades y con algún grado de conciencia ecológica, la acción de estos no espera que el concepto sea definido plenamente por los académicos, ni tampoco por los sistemas jurídicos de los Estados. En la realidad podemos enunciar una especie de ciudadanía económica ${ }^{3}$ que se adelanta a los conceptos teóricos de la ciencia política y de la sociología. En la realidad, los ciudadanos han emprendido acciones desde sus situaciones de vida y sus necesidades, ya sea migrando al interior del país, o bien emigrando hacia otros países en busca de mejores condiciones de vida.

Además, México se ha convertido en un país de tránsito de migrantes, principalmente de Centroamérica hacia Estados Unidos, quienes formalmente no son ciudadanos de México y por lo tanto se encuentran sin la protección jurídica de su país. De esa manera crean una realidad donde el Estado del que proceden se deslinda de facto y, por el que pasan no puede reconocerlos como ciudadanos pues no encajan en su definición de ciudadanía territorialmente concebida. Costa (2010) al respecto afirma que:

\footnotetext{
${ }^{3}$ El término "ciudadanía económica" es referido por Adela Cortina en su libro Ciudadanos del mundo. Hacia una teoría de la ciudadanía, editado por Alianza Madrid, donde expone que en la nueva etapa del desarrollo de la economía del mundo global no es posible continuar encasillando el término ciudadanía en una noción ético política. Es decir, no es comprensible que se aísle lo económico de lo político tratándolos por separado. Al respecto, Pablo González Casanova señaló en su libro La democracia en México que la democracia guarda relación con el hecho de si el individuo tiene zapatos y para comer. Sin embargo, existen aquellos a los que no les agrada hacer esta relación por considerarla obvia, y por lo tanto la ignoran.
} 
El moderno concepto de ciudadanía habría nacido de la mano del de nacionalidad como el concreto contenido jurídico-participativo que se anuda a la pertenencia del individuo a la comunidad, y tiende en la actual era postnacional a desvincular su base teórica de la de nacionalidad y a crear diferentes niveles de pertenencia a la comunidad política, social, económica, cultural, etcétera (Costa, 2010, p. 73).

En plena era de la globalización, la migración figura como una constante que apunta irreversibilidad. La nacionalidad en la práctica se ve rebasada y ya no puede contener a la ciudadanía como algo únicamente político, los individuos migran fundamentalmente por motivos económicos y en general sociales, sin embargo, según algunos analistas políticos la ciudadanía debe seguir enmarcada exclusivamente dentro de lo político, porque "lo que habría que hacer es evitar contaminarse de lo económico, porque lo económico sería peligroso, incluso malo, por consiguiente la ciudadanía no tendría que incluir lo económico" (Conill, 2009, p. 274). Lo anterior presenta un reto al estatus de la ciudadanía que aún responde al sistema de estados nacionales actualmente en desplazamiento por los bloques de estados con objetivos económico-políticos.

Por tanto, el sentido de la ciudadanía requiere ser repensado en relación con la realidad actual y sus acciones concretas, pues vemos un ciudadano activo que se mueve impelido por algún grado de conciencia ecológica y por supervivencia; de facto vemos un perfil de ciudadanía económica, una ciudadanía que busca correspondencia con los efectos de la globalización (Wallerstein, 1999, p. 151). "Lo que se necesita [...] no es aprender que somos ciudadanos del mundo, sino que ocupamos un nicho particular en un mundo desigual” (Wallerstein citado en Velasco, 2013, p. 109).

Reconocer esta situación de vulnerabilidad y crear un nuevo sentido de la situación migratoria que llegó para permanecer, se manifiesta ya como una necesidad. Sin embargo, "la situación real que padecen muchos migrantes desde que emprenden su viaje y buscan asentarse en un nuevo país, e incluso después de haberlo logrado, pone de manifiesto que la implementación de los principios de justicia -incluidos, por supuesto, los derechos 
humanos - sigue siendo concebida desde la perspectiva restringida de los intereses de cada Estado" (Velasco, 2013, p. 109).

La globalización es, en buena medida, la que detona las migraciones de los individuos que el sistema económico ha marginado, y por ello es necesario recurrir a los derechos humanos como la base para modificar el derecho internacional positivo, en tanto no veamos una correspondencia entre la globalización y una ciudadanía global, la cual podría contribuir a pensar el estatus del migrante y sus derechos ciudadanos. En coincidencia con esta idea, Estévez (2012) insiste en retomar los derechos humanos como base de una ciudadanía universal que surge a raíz de los actuales procesos de globalización.

Por eso para los migrantes que se encuentran de paso por nuestro país, "los Estados hacen oídos sordos y el migrante queda atrapado de facto en medio de su viaje en una zona de paso, en una difusa zona normativa donde sus derechos quedan como mínimo en suspenso" (Velasco, 2013, p. 29).

Sin embargo, son individuos que no por eso dejan de actuar, y de realizar acciones ciudadanas, ${ }^{4}$ dondequiera que se encuentren. Así, estas nuevas realidades de los migrantes están creando a su paso espacios ciudadanos de facto, con acciones que podemos calificar de ciudadanas. El concepto actual de ciudadano se ve rebasado por la realidad, que no concuerda con "las reglas escritas y no escritas de la administración pública sobre el espacio público [las cuales] son persistentemente alteradas y puestas en cuestión por las acciones" (Álvarez, 2014, p. 63). El espacio público no es propiedad del Estado ni de los gobiernos, sino de quien lo construye, a los migrantes no se les puede anular su capacidad de acción y menos desconocerla mediante leyes locales, este es el caso de los migrantes inducidos por la realidad del fenómeno de la globalización, provocando el desempleo y la consecuente migración de quienes buscan mejores medios de vida.

\footnotetext{
${ }^{4}$ Este tipo de acciones ciudadanas las entendemos aquí como las acciones que realizan los individuos migrantes como parte de una cultura política adquirida en su lugar de origen o entorno sociopolítico, las cuales llevan consigo y reproducen en cualquier otro espacio físico para buscar su supervivencia.
} 
Lo económico está trabado con lo político, encontramos que los medios de comunicación masiva ejercen una influencia decisiva para crear las nuevas necesidades de la población, y es precisamente la más pobre la que tiende hacia la migración para poder satisfacer los nuevos exhortos al consumo. "Para una gran parte de las personas, ser ciudadano es tener derecho a poseer aquello que otros poseen. Hoy ser ciudadano no es apenas estar al amparo del Estado donde el sujeto nació y tener dentro de él derechos políticos, civiles y sociales. La ciudadanía se refiere a las prácticas sociales y culturales que dan sentido de pertenencia" (García citado en Barreto s.f., p. 1). Dichas prácticas sociales de tipo muy diverso son el fundamento de las prácticas ciudadanas, las cuales apuntan hacia una redefinición del ciudadano y de la ciudadanía en la época de la globalización.

\section{Conclusión}

El proceso de globalización que vive el mundo está desplazando la centralidad política del Estado-nación, sobre todo en los casos de los países económicamente débiles como son los de América Latina, en los que la nueva derecha ha tomado el dominio. Por ello, en estos Estados, como es el caso de México, no existen políticas públicas para la formación ciudadana, ni siquiera considerando la ciudadanía específicamente político-electoral. A la par y de manera inversa en el campo de las medidas de economía, se está dando paso a la formación de mega-Estados como el TLCAN, que son uniones de estados con poder económico y político diferencial conformados básicamente por objetivos económicos.

Las posturas ideológicas que se han apoderado del mundo globalizado son las conservadoras, el mundo se ha derechizado, así que los individuos y su papel ciudadano se definen hoy mediante motivos básicamente económicos y no políticos, La ciudadanía pasa por la criba de la necesidad ingente, y la autonomía de la política se ha vuelto un argumento cada vez menos sostenible, lo cual perfila a la violencia de Estado disfrazada de violencia organizada, y a la cual el Estado muestra cada vez menos voluntad de eliminar.

Las fórmulas económicas más novedosas no contemplan los medios o mecanismos para operar la disminución de la desigualdad social, pues por encima del poder del capital no existe otro poder que pueda someterlo a un orden. En todo caso, las estrategias son aceptar reglas, pero en la práctica no hay poder que pueda obligarlos. 
Este hecho marca un hito que está desestructurando a los Estados-nación más pobres y, consecuentemente, su población tiende a emigrar hacia los países más desarrollados. Esta situación está obligando a hacer cambios en el derecho positivo a partir de los derechos humanos, los cuales deberían realizarse y operar a nivel global, pues los migrantes mientras están en tránsito no se les reconoce un estatus de ciudadanos, pues la ciudadanía aún está atada a la nacionalidad a pesar de que los estados nacionales, hoy globalizados, ya no son unidades cerradas. Al respecto, México es un país de tránsito, cuyo fenómeno merece ser estudiado como elemento de una nueva ciudadanía en tránsito, producida por la migración que se genera como efecto perverso de la globalización y su modelo económico.

En síntesis podemos afirmar lo siguiente:

La ciudadanía ya no puede definirse solo a partir de las tres partes propuestas por Marshall: civil, política y social. Es un hecho que la macroeconomía ha vuelto superlativas estas partes. En la parte civil, Marshall incluyó lo económico, pero pensado como cosa de individuos y no de las grandes corporaciones empresariales y financieras que hoy existen y dominan a los individuos o ciudadanos, con lo que la propiedad individual del ciudadano queda en muchos casos vulnerada y nulificada por los grandes poderes económicos. El mundo se ha complejizado sobremanera.

En la parte política consideró el aspecto político-electoral, sin embargo, hoy el sistema de partidos ha acumulado gran desconfianza, pues se ha aliado con los grandes grupos del poder económico. Y en la parte social, consideró el bienestar económico de los individuos o ciudadanos, y aunque advirtió que esto está en constante cambio, no previó que tal bienestar hoy se ve anulado con la introducción de tecnología que el sistema productivo ha implementado, el cual desplaza la mano de obra, con lo que los ciudadanos particulares tienen que migrar hacia espacios donde puedan conseguir empleo. Teóricamente todo jugador en el mundo global actual debe ser "ciudadano", es requisito para su inclusión en el juego, que se juega en una cancha muy dispareja donde la libertad ya no iguala a los individuos, sino que los hace más desiguales.

Cabe mencionar que, de las tres partes que a juicio de Marshall componen la actividad del ciudadano, dos contienen elementos económicos: la civil y la social, por lo que, en estricto sentido son solo dos las partes principales: la económica y la política. Así, la parte 
económica ha logrado incidir en la política, anteriormente bajo el dominio del Estado, pues ha obtenido el suficiente poder. De esa manera ya no requiere subordinarse a lo político, sus acciones son ya directas y cada vez más abiertas y precipitadas para obtener sus beneficios; si bien ello aumenta los riesgos, estos finalmente pueden ser neutralizados con más protección personal para sus miembros individuales. En el contexto del modelo liberal de ciudadanía, la gran mayoría de ciudadanos quedan vulnerables, marginados y en riesgo de exclusión social, económica y política.

La migración es la esperanza de los excluidos, sobre todo cuando los más ambiciosos en el mundo global se han apoderado de casi todos los recursos para la vida de todos, pues solo unos consumen los recursos que los otros desean tener. De esa manera, el ciudadano de la época de la globalización y del dominio de los más ambiciosos es aquel que posee lo que más puede. 


\section{Bibliografía}

Aboites, Hugo (1999). Viento del Norte, México, UAM/ Plaza y Valdez.

Álvarez Enríquez, Lucía (2013). "Sociedad civil y espacio público" en Ramírez Kuri

Patricia (coordinadora) Las disputas por la ciudad, espacio social y espacio público en contextos urbanos de Latinoamérica y Europa, México, UNAM- Miguel Ángel Porrúa.

Barreto, Margarita (s.f). "Ciudadanía, Globalización y Migraciones", en http://red.pucp.edu.pe/wp-

content/uploads/biblioteca/ciudadaniaglobalizacionymigracionesmargaritabarretto.pdf consultado el 05 de marzo de 2015.

Barreto, Margarita (s.f). "Ciudadanía, Globalización y Migraciones", en http://red.pucp.edu.pe/wp-

content/uploads/biblioteca/ciudadaniaglobalizacionymigracionesmargaritabarretto.pdf consultado el 05 de marzo de 2015.

Cortina, Adela (1997). Ciudadanos del mundo. Hacia una teoría de la ciudadanía, Madrid, Alianza.

Costa, Pietro (2010). Nacionalidad y ciudadanía, Madrid-México, Fontamara.

Conill, Jesús (2009). Ciudadanía económica en la jungla global”, en Guzmán Nora, (Compiladora) Sociedad desarrollo y ciudadanía en México, México, Limusa.

Dahrendorf, Ralf (1997). "La naturaleza cambiante de la ciudadanía", en La política, número 3, Ciudadanía. El debate contemporáneo, Barcelona, Paidós.

Estévez, Ariadna (2012). Human rights, migration, and social conflict towards a decolonized global justice, N.Y. Publisher Palgrave Macmillan.

Finkielkraut, Alain (1982). La nueva derecha norteamericana, Barcelona Anagrama.

Fukuyama, Francis (1992). El fin de la Historia y el último hombre, Madrid, Planeta.

Gzesh, Susan (2012). "Redefinición de la migración forzosa con base en los derechos humanos", en Delgado Wise Raúl y Humberto Márquez Covarrubias (Coordinadores), Desarrollo Desigual y migración forzada. Una mirada desde el sur global, México, U. A. Z./UNESCO/Miguel A. Porrúa.

Heald, David (1997). "Ciudadanía y autonomía”, en La política, número 3, Ciudadanía. El debate contemporáneo, Barcelona, Paidós. 
Hinkelammert, Franz J. (1988). "Democracia y nueva derecha en América Latina", Venezuela, Revista Nueva Sociedad, Número 98 noviembre-diciembre, 1988, pp. 104-115.

Jiménez Edgar (s.f). "La nueva derecha, dilema de la política latinoamericana" en:

http://www.uca.edu.sv/revistarealidad/archivo/4ea09eccdcec7lanuevaderecha.pdf consultado el $24 / 05 / 2015$

Kymlicka, W y Norman, Wayne (1997). "El retorno del ciudadano. Una revisión de la producción reciente en teoría de la ciudadanía”, en La política, número 3, Ciudadanía. El debate contemporáneo, Barcelona, Paidós.

Marshall, T.S. (1997). "Ciudadanía y clase social”, Madrid, Revista Española de Investigaciones Sociológicas (REIS), Número 79, julio-septiembre, pp. 297-344, del Centro de Investigaciones Sociológicas (CIS).

Massey, Doren (2013). "Geografías de responsabilidad”, en Ramírez Kuri Patricia (coordinadora), Las disputas por la ciudad, espacio social y espacio público en contextos urbanos de Latinoamérica y Europa, México, UNAM-Miguel Ángel Porrúa.

Martín, Cristina (2008). El Club Bilderberg. Los amos del mundo, Arcopres, Barcelona.

ONU (2012). en: http://www.un.org/es/sustainablefuture/pdf/Rio+20_FS_Food_SP.pdf, consultado el 24/05/2015.

Piketty, Thomas (2014). El capital en el siglo XXI, España, Fondo de Cultura Económica, España.

Romano, Silvina M. y Gian Carlo Delgado Ramos (s.f). "La nueva derecha en América Latina: una lectura desde Venezuela", en América Latina en movimiento (http://www.alainet.org) consulta 24/05/2015.

Smith, Gordon Connell (1977). Estados Unidos y América Latina, México, Fondo de Cultura Económica.

Velasco Arroyo, Juan Carlos (2013). "Justicia global y el gobierno de las migraciones internacionales”, Revista Estudios Sociales No 47, septiembre-diciembre, pp. 107117. Bogotá, en: 
http://digital.csic.es/bitstream/10261/86621/1/\%2bJusticia\%20global\%20y\%20el\%20gobie rno\%20de\%20las\%20migraciones\%20internacionales.pdf consultada el 05 de marzo de 2015.

Velasco Arroyo, Juan Carlos (2012). “Movilidad Humana y fronteras abiertas”, en Claves de razón práctica $\mathrm{n}^{\mathrm{o}} 219, \quad$ pp. 28-35, en: http://digital.csic.es/bitstream/10261/45259/1/\%2bMovilidad\%20humana\%20y\%20 fronteras\%20abiertas\%20-\%20Claves\%202012.pdf Consultado el 05 de marzo de 2015.

Werz Nikolaus (1995). Pensamiento sociopolítico moderno en América Latina, Venezuela, Editorial, Nueva Sociedad. 